\title{
Serum and v-src increase the level of a CCAAT-binding factor required for transcription from a retroviral long terminal repeat
}

\author{
Anindya Dutta, Mark Y. Stoeckle, and Hidesaburo Hanafusa ${ }^{1}$ \\ The Rockefeller University, New York, New York 10021 USA
}

\begin{abstract}
Transcription from the long terminal repeat (LTR) of Rous sarcoma virus (RSV) in rat 3 Y1 fibroblasts was dependent on the presence of serum. Within $1 \mathrm{hr}$ after addition of serum to a serum-deprived culture, there was a fivefold increase in the level of transcripts initiated at the LTR. This stimulation did not require synthesis of new proteins. The induction of transcription by serum was mostly dependent on two CCAAT boxes in the LTR. Within $1 \mathrm{hr}$ after addition of serum, there was also an increase in the level of a nuclear protein that bound to the two CCAAT boxes, even in the presence of cycloheximide. This serum-induced CCAAT factor also bound CCAAT sequences from other promoters, for example, those of human heat shock protein 70 , human c-Ha-ras, and human histone 1 , but not to the adenovirus origin of replication or the SV40 enhancer core sequence, suggesting that it was related to CP1 or CP2. Expression from the RSV LTR was not dependent on serum in v-src-transformed cells. Using temperature-sensitive v-src, it was shown that the tyrosine kinase activity of the oncogene increased the amount of CCAAT factor that was present in the nucleus. These findings demonstrate that a basal transcription factor, the CCAAT-binding factor, could be a second messenger for transducing a primary signal from serum to the cellular transcriptional apparatus. This also suggests a pathway by which a tyrosine kinase oncogene could influence the transcription of several genes in the nucleus.
\end{abstract}

[Key Words: RSV; LTR; serum; v-src; transcription; CCAAT factor]

Received August 14, 1989; revised version accepted November 14, 1989.

In uninfected chicken embryo fibroblasts (CEFs), the production of endogeneous retroviral RNA and protein was stimulated upon addition of serum to a serum-deprived culture (Chen et al. 1974). This led us to examine whether transcription from an avian retroviral promoter may be influenced by serum. We used the promoter contained in the Rous sarcoma virus long terminal repeat (RSV LTR) as the prototype of an avian retroviral promoter.

Transcription from the RSV LTR is dependent on two types of transcriptional elements. The minimal sequence required for transcription from the LTR in vivo and in vitro (the promoter) is confined to the TATA box, which is at position -25 relative to the transcription start site (Yamamoto et al. 1980; Gilmartin and Parsons 1983; Mitsialis et al. 1983). Transcription from this promoter is influenced by a strong enhancer that has been described and mapped by many groups (Gorman et al. 1982b; Luciw et al. 1983; Laimins et al. 1984; Cullen et al. 1985; Weber and Schaffner 1985; Norton and Coffin 1987; Gowda et al. 1988). The major part of the enhancer maps to the $5^{\prime}$ end of the LTR

${ }^{1}$ Corresponding author.
$(-231$ to -186 , relative to the transcription start site), though some enhancer activity has also been noted immediately $3^{\prime}$ to the SphI site $(-136$ to -120$)$ (Fig. 1).

Nuclear proteins that bind to the LTR have been studied extensively (Karnitz et al. 1987; Sealey and Chalkley 1987; Goodwin 1988; Ryden and Beemon 1989). There are two major DNA-binding proteins that bind to the RSV LTR. One of these binds over the classical enhancer $(-225$ to -188$)$, and the second binds immediately downstream from the SphI site $(-138$ to - 120). Arrigo et al. (1987) and Carlberg et al. (1988) have also demonstrated the existence of an internal enhancer in the gag region of the intact avian retrovirus, which may influence expression from the 5 ' LTR. Furthermore, they have shown that the CCAAT-binding protein CCAAT/enhancer-binding protein (C/EBP) from rat liver extracts (Landschulz et al. 1988) footprints on both the gag enhancer and the enhancer in the $5^{\prime}$ end of the LTR (Carlberg et al. 1988; Ryden and Beemon 1989). Hatamochi et al. (1988) and Maity et al. (1988) reported the presence of a CCAAT-binding protein which, unlike C/EBP, is composed of two heterologous subunits. The factor, CBF, stimulates transcription from the RSV LTR in vitro and footprints over regions -146 to -121 and -82 to -56 of the LTR. 


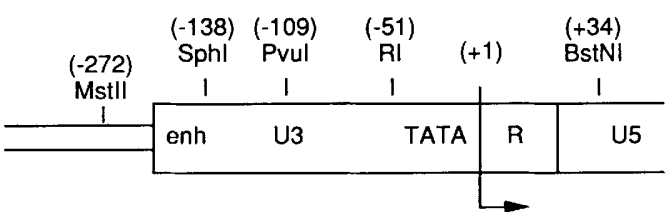

Figure 1. The RSV LTR in RSVCAT and RSVNEO. The structure of the RSV LTR at the $3^{\prime}$ end of the provirus is shown. The Prull-BstNI (converted into a HindIII site) fragment is contained in RSVNEO and RSVCAT. The start site of transcription used by the virus is indicated as +1 , and the positions of all other restriction sites are shown relative to it. The positions of the TATA box and the classical enhancer are indicated. (RI) EcoRI.

In this paper we show that transcription from the RSV LTR was stimulated by serum and demonstrate that this was mediated primarily through the induction of a nuclear CCAAT-binding activity. The induction of transcription and of the CCAAT factor could occur in the absence of new protein synthesis. In addition, the expression from the RSV LTR was not dependent on serum in v-src-transformed cells. Furthermore, v-src increased the level of the same serum-inducible nuclear CCAAT factor that bound to the RSV LTR, thereby suggesting a mechanism by which $\mathrm{v}$-src could stimulate transcription from the RSV LTR and also confer serum independence to transcription from the LTR and many cellular promoters.

\section{Results}

Serum stimulates transcription from the RSV LTR without requiring new protein synthesis

To test whether transcripts initiating in the RSV LTR were induced by serum, we used the plasmids RSVCAT (Gorman et al. 1982b) and RSVNEO. As shown in Figure 1 , both of these contain identical sequences derived from a molecular clone of RSV proviral DNA extending from a $P$ vulI site to a BstNI site /converted into a HindIII sitel. Thus, the whole of U3, R, and part of U5 from the RSV LTR is ligated upstream from the bacterial chloramphenicol acetyl transferase (CAT) gene or the neomycin phosphotransferase (NEO) gene, respectively, such that transcripts initiating in the LTR continue into the CAT or NEO gene. These transcripts are processed at the 3 ' ends of these genes at an SV40 polyadenylation site.

Transient transfection assays were performed with a mixture of $5 \mu \mathrm{g}$ each of RSVCAT and RSVNEO on $3 Y 1$ fibroblasts. The steady-state levels of transcripts initiated accurately from the RSV promoter were measured by $\mathrm{S} 1$ nuclease analysis and were found to be increased relative to total RNA by the addition of serum to the cells (Fig. 2A). The time course of this induction was analyzed using a cell line, 3Y1-NEO, which contained copies of RSVNEO stably integrated in the genome (Fig. 2B). The level of NEO transcripts was induced fivefold within $1 \mathrm{hr}$ of addition of serum, remained high for $5 \mathrm{hr}$, and then declined slowly. S1 nuclease analysis (data not shown) revealed that the NEO transcripts were initiated at the correct site in the LTR.

To examine whether this effect of serum was primary, the serum-starved 3Y1-NEO cells were pretreated with cycloheximide at $50 \mu \mathrm{g} / \mathrm{ml}$ for $15 \mathrm{~min}$ before the addition of serum. Cycloheximide treatment alone increased the NEO RNA level twofold (Fig. 2B), and the additional fivefold induction by serum was resistant to cycloheximide, showing that the effect of serum was primary.

Nuclear run-on assays done on 3Y1-NEO cells (Fig. $2 \mathrm{C}$ ), showed that transcription from the RSV LTR into the NEO gene was stimulated within $1 \mathrm{hr}$ of addition of serum. $\beta$-Tubulin and $28 \mathrm{~S}$ rRNA genes served as negative controls. No signal was detected using $\phi X 174$ DNA as a control for nonspecific hybridization, and the stimulation of transcription from the LTR was maintained even after $6 \mathrm{hr}$ of incubation with serum (data not shown).

To determine whether serum influenced the level of viral RNA in CEFs, a transformation-defective variant of RSV, td107, was used (Wang et al. 1984). This virus had a deletion of the v-src gene; therefore, any effects that pp60 $0^{\mathrm{v}-s \mathrm{c}}$ might have on expression from the LTR were avoided. CEFs infected with td107 were starved of serum for $48 \mathrm{hr}$ and then treated with serum in the absence or presence of cycloheximide. Serum alone increased the level of td107 genomic RNA (Fig. 2D, lanes 1 and 2). Cycloheximide alone increased the level of viral RNA (lane 3 ), and an additional stimulation by serum was not seen. The inability to demonstrate an effect of serum in CEFs in the presence of cycloheximide could have resulted from the sensitivity of the CEFs to cycloheximide for 12 $\mathrm{hr}$, and the issue was not pursued any further.

\section{Two CCAAT box sequences in the RSV LTR are} critical for transcription after the addition of serum

To map the elements in the LTR upstream from the TATA box that were most important for transcription after the addition of serum, a series of deletions were made in RSVCAT; the amount of CAT enzyme activity produced from each of the deletion derivatives, $12 \mathrm{hr}$ after the addition of serum to a serum-deprived culture, was determined using transient transfection assays. These CAT activities were compared to that obtained from RSVCAT in parallel transfections (Fig. 3).

$\triangle$ RSCAT (deletion from -51 to -138 ) decreased the CAT activity to $6.5 \%$ of the level of RSVCAT and was the minimal deletion that resulted in promoter activity that was significantly different from the intact LTR.

Two CCAAT sequences were noted in the antisense strand of the EcoRI-SphI (-51 to - 138, RS fragment) sequence deleted in $\triangle$ RSCAT (Fig. 4). A CCAAT factor footprints over these sequences and stimulates transcription from the RSV LTR in vitro (Hatamochi et al. 1988; Maity et al. 1988). Thus, we tested whether these CCAAT sequences were involved in the activity of the LTR on addition of serum to the cells by making the mutations shown in Figure 4 in the RSV LTR of RSV CAT. These mutants were analyzed in the same way as 




Figure 2. Serum induces transcription from the RSV LTR in the absence of new protein synthesis. $(A) \mathrm{S} 1$ nuclease analysis of total RNA from 3 Y1 transfected with RSVNEO and RSVCAT. (- ) Cells in $0 \%$ DEM for $48 \mathrm{hr} ;|+|$ cells in $0 \%$ DEM for $48 \mathrm{hr}$, followed by addition of calf serum to $10 \%$ (vol/vol). Incubation was continued for another $6 \mathrm{hr}$. Probes RSVNEO and RSVCAT were cut and labeled at unique $N$ coI sites in the NEO and CAT gene, respectively. The sizes of the fragments protected by correctly initiated transcripts are 950 bases for RSVNEO and 577 bases for RSVCAT. (B) Induction of NEO RNA in 3Y1-NEO. Serum was added to 10\% to cultures starved of serum for $48 \mathrm{hr}$, total RNA was harvested, and $3 \mu \mathrm{g}$ of RNA was used per slot in the slot blots (S). In parallel plates, cycloheximide was added to $50 \mu \mathrm{g} / \mathrm{ml}$ for $15 \mathrm{~min}$ before adding serum. In this case, $1 \mu \mathrm{g}$ of RNA was used per slot (CH $+\mathrm{S}$ ). Numbers indicate hours after serum addition. The slot blots were quantitated by densitometry; the NEO RNA levels at the various time points were normalized to the $0 \mathrm{hr}$ (S) value and plotted. (Y-axis) Fold stimulation of NEO RNA level relative to 0 hr (S); (X-axis) hours after addition of serum. (C) Nuclear run-on transcripts were prepared from $3 \mathrm{Y} 1-\mathrm{NEO}, 48 \mathrm{hr}$ after serum deprivation $(-)$ and $1 \mathrm{hr}$ after addition of serum to $10 \%$ to a serum-deprived culture $(+1$. The probes used are shown at right and described in Methods. The signal hybridizing to pUC18 resulted from readthrough transcripts from cellular promoters into the integrated pBR322 sequences. However, the NEO signal itself was detected with a fragment from RSVNEO, which was devoid of any DNA that could hybridize to the pBR322 background. $(D)$ Equal quantities of total RNA from td107-infected CEFs analyzed on a Northern blot using as a probe the 4.6-kb XhoI fragment from the gag-pol region of a molecular clone of SR-A RSV proviral DNA. The genomic RNA is shown. (Lanes 1 and 3) Cells in 0\% Scherer's medium for $60 \mathrm{hr}$; (lanes 2 and 4) cells in $0 \%$ Scherer's medium for $48 \mathrm{hr}$, followed by $12 \mathrm{hr}$ in the same medium supplemented with $5 \%$ calf serum; (lanes 3 and 4) cycloheximide added to $50 \mu \mathrm{g} / \mathrm{ml}$ after $48 \mathrm{hr}$ of serum deprivation.

the deletion plasmids, and the results are presented in Figure 3. pm80CAT produced significantly lower CAT activity compared to RSVCAT, indicating that the promoter proximal CCAAT box (" 80 ") was important for expression from the LTR after the addition of serum. Mutation of the distal CCAAT element ("140") did not cause a significant decrease in CAT activity in the intact LTR (pm140CAT) but did show a significantly lower promoter activity compared to RSVCAT when combined with a deletion of the SM fragment ( $\triangle$ SM140CAT). The deletion of the SM fragment alone ( $\triangle S M C A T)$ did not significantly weaken the promoter activity compared to RSVCAT, suggesting that the low CAT activity from $\triangle$ SM140CAT indicates that the distal CCAAT element (140) also plays a role in serum-stimulated transcription from the LTR. The higher CAT activity of pm814CAT, relative to pm80CAT, is discussed later.

\section{CCAAT sequences in the LTR are responsible for both basal level of transcription and induction of transcription by serum}

The CCAAT sequences that were found to be critical for transcription from the RSV LTR on addition of serum could be responsible for maintaining the basal level of transcription in the absence of serum, for the induction of transcription by serum, or for both. Wild-type RSV
LTR directing a deletion derivative of the NEO gene was cotransfected as an internal positive control into $3 \mathrm{Y} 1$ cells with various test LTRs driving the intact NEO gene. The cells were serum-deprived for $48 \mathrm{hr}$, and the RNA was harvested directly or $2 \mathrm{hr}$ after the addition of serum. The results of an S1 nuclease assay with equal quantities of RNA in each lane are presented in Figure 5. The SM and RS fragments contributed equally to the basal level of transcription, but the $\Delta R S$ construct also showed a $60 \%$ decrease in serum induction relative to wild-type LTR. The pm80 LTR also showed a $60 \%$ decrease in the induction relative to wild type. However both the 80 and 140 CCAAT sequences had to be mutated for basal level of expression to decrease (as in pm814). The finding that the 80 CCAAT element mediates half of the serum responsiveness of the LTR has been confirmed in a different series of transient expression assays, using CAT plasmids as the test plasmids and RSVNEO as the internal positive control. pm80CAT again showed a $60 \%$ decrease in induction relative to RSVCAT, though, in this case, the basal level of pm80CAT was also decreased, much like $\triangle$ RSNEO in Figure 5. Thus, both the CCAAT sequences were necessary for basal level of expression, and the promoter proximal CCAAT (80) element was also responsible for mediating at least half of the serum stimulatory signal. The relative importance of the two CCAAT sequences for serum responsiveness is discussed later. 


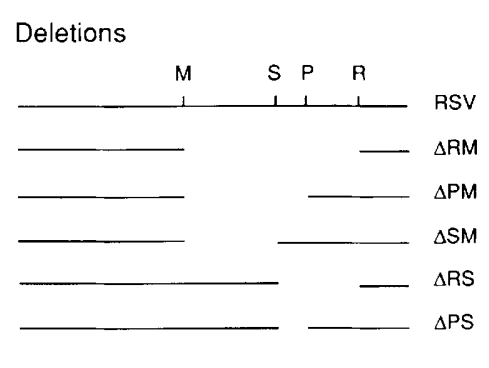

$\begin{array}{ccc}\begin{array}{c}\text { CAT } \\ \text { Activity } \\ (\%)\end{array} & \text { S.D. } & \text { N } \\ 100 & 18 & 13 \\ 2 & 1 & 4 \\ 37 & 1 & 2 \\ 98 & 58 & 10 \\ 6 & 2 & 4 \\ 53 & 40 & 3\end{array}$

Point-mutations

\begin{tabular}{llllll}
\hline & pm 80 & 15 & 4 & 6 \\
\hline & pm 120 & 97 & 36 & 4 \\
\hline & pm 140 & 72 & 19 & 6 \\
\hline & pm 814 & 51 & 22 & 7
\end{tabular}

Deletions and point-mutations

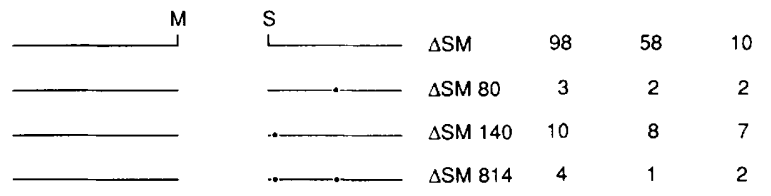

Figure 3. Mutations in the RSV LTR define elements that are critical for expression from the LTR upon addition of serum. Ten micrograms of RSVCAT or its derivatives was transfected into $3 \mathrm{Y} 1$. The cells were starved of serum for $48 \mathrm{hr}$, treated with $10 \%$ calf serum, and harvested after an additional $12 \mathrm{hr}$. The CAT activity obtained from equal quantities of protein from each transfection is normalized to that obtained from plates transfected with RSVCAT in parallel (100\%). The mean result for each plasmid is shown, along with the standard deviation (S.D.) and number of independent transfections (N). The names of the plasmids are given, along with schematics of the mutations. (RSV) RSVCAT; ( $\triangle \mathrm{SM}) \triangle \mathrm{SMCAT} ;(\mathrm{pm} 80)$ pm80CAT; $(\triangle S M 80) \triangle S M 80 C A T$, etc. Restriction enzyme sites indicated for RSVCAT are EcoRI (R), PvuI (P), SphI (S), and MstII (M) (Fig. 1). In the schematics, gaps indicate deletions made using the restriction enzyme sites shown, and dots indicate point mutations (Fig. 4).

Serum induces the appearance of a nuclear protein that binds to the RS fragment

Gel mobility-shift assay using equal quantities of protein from nuclear extracts of serum-starved cells before and after the addition of serum (Fig. 6) revealed that the abundance of a nuclear protein that bound specifically to the RS fragment was increased by serum (cf. lanes 1 and 3). In contrast, the nuclear protein(s) binding to the SM fragment (lanes 5-8) was not induced to the same extent by serum (lanes 5 and 7). The diffuse bands produced by the SM fragment make quantitation of the effect of serum on the SM factor difficult; however, the serum induction of the RS factor is confirmed in Figure 8, below, where another nuclear factor, ISGF1, is used as a negative control.

The serum-inducible factor binds to the two CCAAT box sequences

To determine whether the serum-induced nuclear factor bound to the RS at the CCAAT boxes, the point mutants made in the RS fragment (Fig. 4) were used to compete for the RS-binding factor in a gel mobility-shift assay (Fig. 7). Mutants that retained even one of their CCAAT boxes (pC-80, pC-140) still competed for the RS-binding factor, whereas mutants that had lost both their CCAAT boxes (pC-814) failed to compete for the RS-binding factor. Thus, the serum-inducible nuclear protein bound to the RS fragment through either of the CCAAT box sequences responsible for most of the serum responsiveness of the RSV LTR.

The PVuI-SphI (PS) fragment cloned in pUC18 (pAD5; Fig. 4), containing only the distal (140) CCAAT element, competed for the RS-binding factor (data not shown). The competition was abolished by a mutation in the PS fragment that changed the AA of CCAAT (pAD5pml; Fig. 4).

Time course studies showed an increase in the level of CCAAT factor per microgram of nuclear protein within $1 \mathrm{hr}$ of addition of serum (data not shown). The level continued increasing up to $3 \mathrm{hr}$ and declined slightly below the maximum at $6 \mathrm{hr}$ after serum addition.

The number of specific DNA-protein complexes seen with the RS or PS fragments appeared to increase from one to two, with increasing concentration of protein in the nuclear extract (Figs. 6-10). When one band was seen, its mobility corresponded to that of the upper of the two bands.

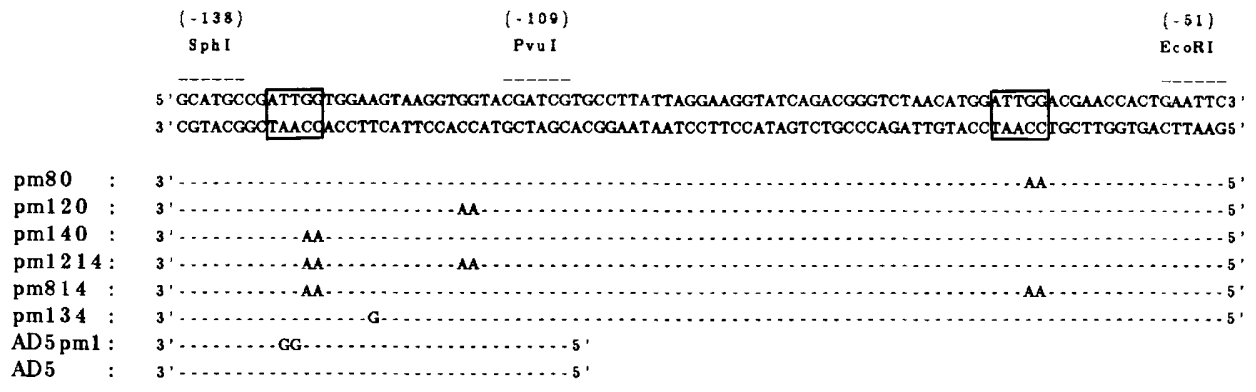

Figure 4. The sequence of the EcoRI-SphI (RS) fragment of the LTR and point mutations made in it. The entire fragment was cloned into $\mathrm{pEMBL} 18$ to give $\mathrm{pC}$. The lines below indicate the mutations made in this fragment (only the lower strand is represented) and the names of the corresponding plasmids. pAD5 and pAD5pm1 are derivatives of pUC18, containing the oligonucleotides shown. The CCAAT elements in the antisense strand are boxed. 


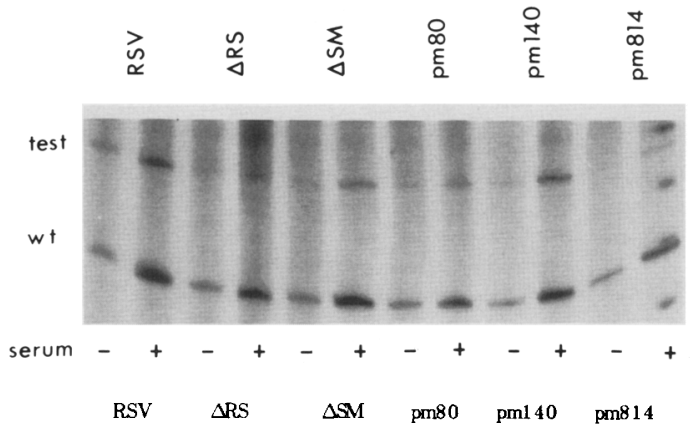

BASAL LEVEL OF TEST RELATIVE

TO BASAL LEVEL OF WIDD-TYPE

INDUCTION RATIO OF TEST

INDUCTION RATIO OF WILD-TYPE
Figure 5. The RS fragment and the CCAAT sequences in it are required for both basal level of transcription and the induction of transcription by serum. RSV miniNEO /wild-type LTR driving a deletion derivative of the NEO gene, internal control) and a test plasmid (test LTR driving the NEO gene) were cotransfected into 3Y1 $(10 \mu \mathrm{g}$ of each plasmid per plate). Total RNA was harvested after $48 \mathrm{hr}$ of serum deprivation (- serum) or $2 \mathrm{hr}$ after addition of serum to $10 \%$ to a serum-deprived culture transfected in parallel ( + serum). The results of an S1 nuclease analysis are shown, using RSVNEO plasmid labeled at the $N$ coI site as a probe. (wt) Signal from the RSV miniNEO gene; (test) signal from the cotransfected test LTR driving the intact NEO gene. The test LTR for each pair of lanes is indicated (top). Lighter exposures of the gel using preflashed film were scanned by soft laser densitometry, and the strengths of the various signals quantitated. The results are tabulated (bottom).

Basal level) Level of transcripts in the absence of serum. If a mutation does not affect the test relative to basal level of wild type is expected to be 0.4 , as when the test LTR was the intact RSV LTR. (Induction ratio) Ratio of signal from serum-stimulated cells to that from serum-starved cells. For each pair of lanes, the induction ratio of the test is expected to be equal to the induction ratio of the wt LTR if the test LTR does not have a mutation in an element that mediates the serum responsiveness. The extra bands in the pm814 + serum lane are a result of spillover of molecular-size markers from the adjoining lane.

\section{Serum induces the CCAAT factor in the presence of cycloheximide}

Serum-starved $3 \mathrm{Y} 1$ cells were treated with cycloheximide for $15 \mathrm{~min}$ before serum was added, and nuclear extracts were prepared (Fig. 8). The level of CCAATbinding activity was still induced by serum in the presence of cycloheximide. As a negative control, we measured the level of factor in the same extracts binding to

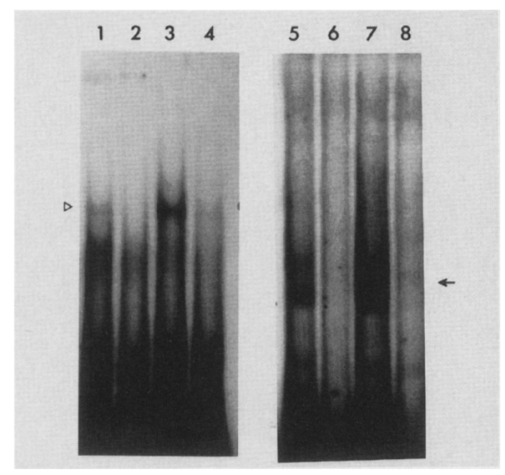

Figure 6. Induction by serum of a nuclear factor binding to the RS fragment. Gel mobility-shift analysis shows the induction by serum of a nuclear protein binding to the RS fragment. Equal quantities of protein are used in each lane. (Left) Probe is the EcoRI-SphI fragment (RS) of the RSV LTR; (right) probe is the SphI-MstII fragment (SM) of the LTR. The competitors in the reactions were as follows: (Lanes 1, 3, 5, and 7) pEMBL 18; (lanes 2 and 4) pC (pEMBL18 with the RS fragment cloned in it); (lanes 6 and 8$) \mathrm{pB}$ (pEMBL18 with the SM fragment cloned in it). The nuclear extracts used were from serum-starved $3 \mathrm{Y} 1$ cells (lanes 1,2,5, and 6) or from 3Y1 cells treated with $10 \%$ serum for $2 \mathrm{hr}$ after serum starvation (lanes $3,4,7$, and 8). Specific DNA-protein complexes are marked for RS $(\triangle)$ and $S M$ (arrow). an interferon-responsive element, specifically the sequence from -190 to -60 of the promoter of the interferon-stimulated gene for guanylate-binding protein (GBP) (Decker et al. 1989). This element has been shown to bind to a factor, called ISGF1, present in nuclei of cells even in the absence of interferon (Levy et al. 1988; D. Lew, pers. comm.). The intensity of the ISGF1 band shown in Figure 8 was decreased upon competition by cold DNA and represented the only specific DNA-protein complex in those gel mobility-shift assays /data not shown). ISGFl was not induced to the same extent as the CCAAT factor and therefore serves as a control for artifactual differences in the quality of the extracts prepared under the two conditions. The amount of cycloheximide used was sufficient to inhibit $97 \%$ of protein synthesis in fibroblasts (M.Y. Stoeckle, unpubl.).

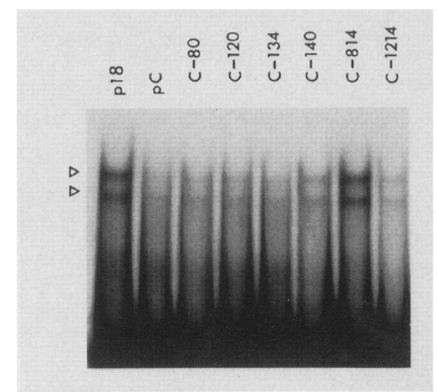

Figure 7. The serum-induced nuclear protein binds to the CCAAT sequences in the LTR. Gel mobility-shift assay with the RS fragment and nuclear extract from serum-stimulated $3 \mathrm{Y} 1$ cells. The plasmid present in competition in each reaction is indicated above each lane: $(\mathrm{p} 18)$ pEMBL18; $(\mathrm{C}-80) \mathrm{pC}$ with the pm80 mutation, etc. (Fig. 4). ( $\triangle$ ) Specific DNA-protein complexes. 


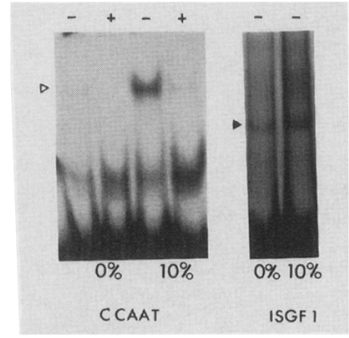

Figure 8. Serum induction of CCAAT factor in the presence of cycloheximide. $3 \mathrm{Y} 1$ cells starved of serum for $72 \mathrm{hr}$ were treated with cycloheximide $(10 \mu \mathrm{g} / \mathrm{ml})$ for $15 \mathrm{~min}$ and then exposed to either BSA at $4 \mathrm{mg} / \mathrm{ml}(0 \%$ serum $)$ or $10 \%$ calf serum; nuclear extracts were made $2 \mathrm{hr}$ later. The $0 \%$ serum plates were treated with the same amount of protein as contained in the serum added to the $10 \%$ serum plates to control for contamination of the nuclear extracts with protein from the medium. The source of the extract is indicated at bottom. Equal quantities of protein were used in each reaction. (Left) The probe was the PS fragment made by annealing oligonucleotides ANDU2 and 3 ; (right) the probe was the -190 to -60 DNA fragment from the promoter of the interferon-inducible gene GBP (Decker et al. 1989). (Left) - Competitor lanes contained pAD5pml; + competitor lanes contained pAD5. (Right) Competitor lanes contained pUCl8. $(\triangle)$ Specific DNA-protein complex with PS fragment and CCAAT factor; (A) specific DNA-protein complex with the GBP promoter fragment and ISGF1.

The CCAAT box-binding factor that binds to the RSV $L T R$ belongs to the CP1,2 class of factors

The serum-inducible CCAAT box-binding factor that bound to the RSV LTR could resemble any of the CCAAT factors that have been characterized previously (Dorn et al. 1987; Chodosh et al. 1988; Gil et al. 1988; Hatamochi et al. 1988; Landschulz et al. 1988; Paonessa et al. 1988; Santoro et al. 1988). Double-stranded synthetic oligonucleotides that have been used to define these known CCAAT factors were used to compete for the protein binding to the PS fragment of the LTR. Only the oligonucleotides that bind the CP1,2 class of factors (the human Hsp70 CCAAT oligonucleotide, the human histone H1 CCAAT oligonucleotide, and the c-Ha-ras CCAAT oligonucleotide) competed for the LTR CCAAT factor effectively (Fig. 9A). These oligonucleotides were all of approximately the same size as the PS oligonucleotide, so that if each of them bound proteins of similar size, the DNA-protein complexes formed would all be expected to have similar mobilities (Bading 1988). Gel mobility-shift assays done with each of these oligonucleotides showed that they formed DNA-protein complexes of the same size as that formed by the LTR CCAAT sequence (Fig. 9B). In both of these experiments, the NF1-binding oligonucleotide from the adenovirus origin of replication and the C/EBP-binding sequence from the SV40 enhancer behaved differently from the CP1,2-binding elements. From these results, we conclude that the serum-inducible CCAAT factor that bound to the RSV LTR belonged to the CP1,2 class. This supports results of Hatamochi et al. (1988), who purified a CCAAT factor that bound to the RS fragment of the RSV LTR and found it to be a multisubunit protein, like CP1 or CP2, rather than like CTF1/NF1 (Santoro et al. 1988) or C/EBP (Landschulz et al. 1988).

Tyrosine kinase activity of $V$-src protein stimulates the level of CCAAT factor

When RSVCAT was transfected into $3 Y 1$ cells, which were then either serum-deprived or maintained in 5\% calf serum containing Dulbecco's modified Eagle medium (DEM) for $36 \mathrm{hr}$, the CAT activity per plate was fivefold less in the cells that had been starved of serum (Table 1). This was seen in both a sparse culture of $3 \mathrm{Y} 1$ and in a confluent, stationary culture of $3 \mathrm{Y} 1$, suggesting that proliferation of the cells was not required for this effect. In v-src-transformed 3Y1 (SR-3Y1) cells, in contrast, serum deprivation had no effect on the level of CAT activity obtained per plate. This suggested that pp $60^{\text {v-src }}$ substituted for the serum requirement of expression from the RSV LTR. Using temperature-sensitive v-src-transformed 3Y1 (NY68-3Y1) cells, we have shown that the tyrosine kinase activity of pp $60^{v-s r c}$ has both a serum-sparing and a stimulatory effect on the level of RNA expressed from the RSV LTR (Dutta et al. 1990).

Because we found that serum stimulated transcription from the RSV LTR by increasing the level of a nuclear CCAAT-binding factor, we examined the stimulatory effect of $\mathrm{v}$-src protein on the LTR for a similar mechanism. As shown in Figure 10, when NY68-3Y1 cells were shifted up to the restrictive temperature $\left(39^{\circ} \mathrm{C}\right)$, the amount of CCAAT-binding activity per microgram of nuclear extract protein was decreased relative to that of cells maintained at the permissive temperature $\left(34^{\circ} \mathrm{C}\right)$. Conversely, the level of CCAAT factor was increased when NY68-3Y1 cells were shifted down to the permissive temperature. These effects were not seen with ISGF1 (Fig. 10, right) or with 3Y1 cells that did not contain the temperature-sensitive $\mathrm{v}$-src gene (bottom). Thus, elevation of the level of a nuclear CCAAT factor could contribute to the stimulation of the RSV LTR by pp60 ${ }^{\mathrm{v}-s \mathrm{sc}}$ and account for the serum independence of expression from the LTR in SR-3Y1.

\section{Discussion}

Serum responsiveness of the RSV LTR

The fivefold induction of gene expression from the RSV LTR within $1 \mathrm{hr}$ of addition of serum is relatively small in magnitude but of considerable significance. We have demonstrated that the induction is seen at the transcriptional level and persists for at least $6 \mathrm{hr}$, is reproducible, is a primary effect, and is overridden by v-src. The magnitude of the induction compares favorably with the threefold induction by TPA of $\mathrm{SV}_{2} \mathrm{CAT}$ and even of a promoter with multimers of the TRE-responsive AP-1 element (Lee et al. 1987). This level of induction is also comparable to the response of the Hsp70 promoter to serum (10-fold after 10-18 hr) and of the c-Ha-ras promoter to insulin-like growth factor 1 and epidermal 

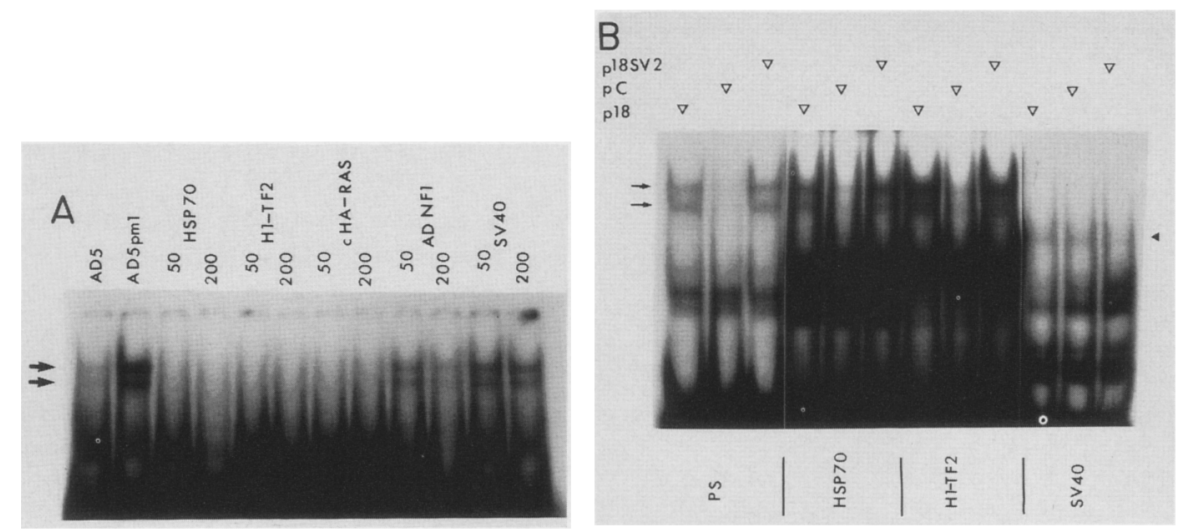

Figure 9. The serum-induced factor binds to other CCAAT sequences. $(A)$ Other CCAAT oligonucleotides compete for the CCAAT factor that binds to the RSV LTR. The PS fragment was labeled and a gel mobility-shift assay performed using nuclear extracts from serum-stimulated $3 \mathrm{Y} 1$ cells. pAD5 was present in the reaction in the first lane and pAD5pml in all the other lanes. The oligonucleotides (and their amounts in $\mathrm{ng}$ ) used in competition are shown above the corresponding lanes. One nanogram of the labeled probe was used in each reaction. (Hsp70) CCAAT box from the human heat shock protein 70 promoter; (c-Ha-ras) CCAAT box from human cellular Harvey ras proto-oncogene; (H1-TF2) CCAAT box from human histone H1 promoter; (Ad-NF1) nuclear factor 1-binding site from adenovirus 2; (SV40) enhancer core sequence of SV40 72-bp repeats. Specific DNA-protein complexes are marked with arrows. (B) The CCAAT factor forms the same sized complex with the PS oligonucleotide as with the other oligonucleotides that compete for the RSV LTR CCAAT factor. The oligonucleotides shown below the lanes were labeled and used in gel mobility-shift assays with the same nuclear extracts as in $A$. The plasmid used in competition in each reaction is shown above each lane. Arrows indicate: Specific DNA-protein complexes formed on the PS, Hsp70, and H1-TF2 oligonucleotides. (A) Specific complex formed on the SV40 enhancer core oligonucleotide. Because of differences in the specific activities of the probes, the six middle lanes are from a lighter exposure of the autoradiograph. All lanes are from the same gel.

growth factor (EGF) (5- to 7-fold after $16 \mathrm{hr}$ ) (Wu et al. 1986; Lu et al. 1989).

However, the most significant finding about the serum induction of the LTR, however, is that it is mediated by a ubiquitous transcriptional element formerly believed to play a role only in basal level of transcription. The CCAAT elements mediate more than half the serum responsiveness of the LTR. We believe that both of the CCAAT sequences are equivalent in this function because they bind the same transcriptional factors. Furthermore, four copies of the PS fragment (containing the 140 CCAAT element), cloned upstream from the -51 site in the RSV LTR, confer serum responsiveness to the promoter (A. Dutta, unpubl.). The apparently greater importance of the 80 CCAAT element in mediating serum responsiveness may be the result of its location relative to the TATA box and not the result of innate differences in the two CCAAT elements. This is supported by the study of Gilmartin and Parsons (1983), which showed normal expression from the RSV LTR upon deletion of the 80 CCAAT sequence. Such deletions would bring the upstream 140 CCAAT sequence closer to the TATA box in a position where it can compensate for the loss of the 80 CCAAT element. The finding that the RP (EcoRI-PvuI) and the PS (PvuI-SphI) fragments have equivalent roles in expression from the LTR also suggests the equivalence of the two CCAAT elements (Cullen et al. 1985).

An additional role of the CCAAT sequences in transcription termination may account for one anomalous result. The introduction of the 140 mutation into an LTR that already had a mutation in the proximal CCAAT box (pm814CAT) caused an increase in serum- stimulated CAT activity relative to pm80CAT. This was not seen when the SM fragment was deleted (cf. $\triangle$ SM814CAT and $\triangle$ SM80CAT). The increased CAT activity obtained from the pm814 LTR relative to the pm80 LTR was not reflected in the levels of correctly initiated transcripts, as mapped by S1 nuclease assays (Fig. 5). An explanation of these anomalous results could lie in transcripts initiating in the SM fragment of the RSV LTR (Mitsialis et al. 1983), which are normally terminated by the CCAAT sequences in the antisense strand, as has been reported recently in another promoter (Connelly and Manley 1989).

Table 1. Expression from the RSV LTR is serum independent in $\mathrm{V}$-src-transformed cells

\begin{tabular}{lcc}
\hline & \multicolumn{2}{c}{ CAT activity per plate } \\
\cline { 2 - 3 } & $5 \%$ DEM & $0 \%$ DEM \\
\hline Sparse 3 Y1 $^{\mathrm{a}}$ & 5.6 & 0.8 \\
${\text { Confluent } 3 \text { l }^{\mathrm{b}}}_{\text {SR-3Y1 }^{\mathrm{c}}}$ & 38.5 & 9.8 \\
& 6.2 & 5.8 \\
\hline
\end{tabular}

RSVCAT $(1 \mu \mathrm{g})$ and salmon-sperm DNA $(9 \mu \mathrm{g})$ were transfected into the cells in 5\% DEM. The cultures were washed and maintained in either $5 \%$ DEM or $0 \%$ DEM (as indicated) for $36 \mathrm{hr}$ before harvesting for CAT assays. One plate equivalent of each lysate was used, and the CAT activities expressed as percent chloramphenicol acetylated after $40 \mathrm{~min}$ of incubation at $37^{\circ} \mathrm{C}$. a3Y1 plated at $3 \times 10^{5}$ cells per $60-\mathrm{mm}$ plate in $5 \%$ DEM $16 \mathrm{hr}$ before transfection.

b3Y1 plated at $5 \times 10^{5}$ cells per plate in $5 \%$ DEM $90 \mathrm{hr}$ before transfection. The confluent culture of $3 \mathrm{Y} 1$ takes up much more DNA than the sparse culture because none of the DNA is lost by being precipitated on the dish between cells.

cSR-A RSV-transformed 3 Y1 cells plated as with sparse $3 Y 1$. 




Figure 10. v-src increases the level of CCAAT-binding factor. Gel mobility-shift assays performed with the same probes as in Fig. 8. The source of nuclear extracts is indicated at right and at top. Equal quantities of protein were used for all the lanes in the same row. The cells were maintained at the final temperature for at least $72 \mathrm{hr}$ before making nuclear extracts. The culture medium ( $10 \%$ fetal calf serum DEM) was changed daily, with the last change $24 \mathrm{hr}$ before harvesting the cells. All extracts used in a row of lanes were prepared in parallel (ts3Y1) NY68-3Y1. All other labels are the same as in Fig. 8. ( $\triangle$ and $\mathbf{A})$ the specific DNA-protein complexes formed by the CCAAT factor on PS oligonucleotides and ISGF1 on the GBP promoter fragment, respectively.

Because the CCAAT elements account for $\sim 60 \%$ of the serum responsiveness of the LTR, there must be additional serum-responsive elements in the LTR, possible candidates being the SM fragment or even the TATA box.

Our results confirm the findings of Chen et al. (1974) that expression from an avian retroviral promoter is induced by serum in nontransformed CEFs. The finding that $\mathrm{pp} 6 \mathrm{O}^{\mathrm{v}-\mathrm{src}}$ overrides this serum dependence suggests a reason for the frequent transduction of tyrosine kinase proto-oncogenes by avian retroviruses. The effect of pp $60^{\mathrm{r}-\mathrm{src}}$ may explain the differences in reports on how serum influences the titer of retroviruses from infected CEFs. No decrease in virus titer was found on serum deprivation of CEFs transformed by RSV (Temin 1967; Humphries and Temin 1972, 1974; Leong et al. 1972), whereas Bell et al. (1975) reported a significant decrease in virus titer upon serum deprivation of CEFs infected with temperature-sensitive mutants of RSV and held at the restrictive temperature. The discrepancy could be explained if the tyrosine kinase activity of $\mathrm{pp} 60^{\mathrm{v}-s \mathrm{sc}} \mathrm{di}-$ minished the serum dependence of transcription from the RSV LTR. This unexpected affirmation of our results emphasizes that, despite its small magnitude, the serum responsiveness of the LTR is real and of wide-ranging importance.

CCAAT factor as a novel second messenger for signal transduction from serum to the cellular transcriptional apparatus

The primary effect of serum on the RSV LTR suggests that the transduction of the signal from serum outside the cell to the nucleus is direct and involves modification of pre-existing proteins. Because mutations in the CCAAT sequences interfere with the binding of a nuclear protein to the LTR and decrease its serum responsiveness, we propose that it is the CCAAT box-binding factor that mediates the primary signal from serum. This hypothesis is supported by the observed increase in CCAAT-binding activity per microgram of protein in the nuclear extracts of cells exposed to serum even in the presence of cycloheximide. Elucidation of the mode of activation of CCAAT-binding factor will shed light on a novel signal-transduction pathway.

Although serum induces the nuclear CCAAT boxbinding factor without new protein synthesis, the magnitude of the induction is greater in the presence of protein synthesis (A. Dutta, unpubl.). Thus, serum may also stimulate the synthesis of a new CCAAT box-binding factor, perhaps by increasing the synthesis of the mRNA coding for it, analogous to the stimulation of transcription of the c-jun gene by EGF (Quantin and Breathnach 1988).

\section{Activation of the CCAAT factor pathway by serum may contribute to the serum induction of many cellular genes}

The fact that transcription can be stimulated from the RSV LTR by serum adds the RSV LTR to a list of promoters that behave similarly, for example, the promoters of c-fos, c-myc, c-junB, and actin (Greenberg and Ziff 1984; Ryder et al. 1988 and references therein). Serum stimulation of transcription appears to be a generalized phenomenon common to many cellular promoters. A burst of $\left[{ }^{3} \mathrm{H}\right]$ uridine incorporation is seen on addition of serum to a confluent culture of $3 \mathrm{~T} 3$ fibroblasts (Todaro et al. 1965), and as many as 80 genes have been identified in one study to be induced by serum (Almendral et al. 1988). The finding that the serum respon- 
siveness of the RSV LTR is mediated mostly by a CCAAT box-binding factor that acts on many cellular promoters provides a mechanism for such a generalized activation of transcription.

Two other promoters may also be induced by serum through this newly discovered CCAAT factor pathway. The Hsp70 promoter is responsive to serum, and the absolute level of transcription upon addition of serum is strongly dependent on the presence of an intact CCAAT element (Wu et al. 1986). The major element responsible for the induction has been suggested to be a purine-rich sequence immediately downstream from the CCAAT element. However, the HindIII linker used for generating the deletions described by $\mathrm{Wu}$ et al. could recreate a CCAAG sequence, which has been shown to be at least $50 \%$ as active as a CCAAT sequence in its ability to stimulate transcription (Graves et al. 1986). Because the Hsp70 CCAAT sequence binds the serum-induced CCAAT factor, we suggest that both the basal level and the serum induction of the Hsp70 promoter are dependent on the CCAAT element, as with the RSV LTR.

A similar prediction is made for the c-Ha-ras promoter because the CCAAT element from this promoter bound the serum-induced CCAAT factor and because this promoter is also responsive to serum with kinetics, comparable to the RSV LTR (Lu et al. 1989).

\section{Constitutive activation of the CCAAT factor pathway by oncogenes}

The stimulatory effect of pp60 $60^{\text {v-src }}$ on the CCAAT factor was much slower than that of serum. This slow change appears to be a reflection of the slow increase in phosphotyrosine-containing proteins in NY68-3Yl upon shift down to the permissive temperature (Dutta et al. 1990). Because of these slow kinetics, it was not possible to examine directly whether new protein synthesis was required for the stimulation of CCAAT-binding activity by pp $60^{\mathrm{v}-s r c}$. Thus, unlike serum, the effect of v-src protein on the level of CCAAT factor that we have demonstrated could certainly involve the synthesis of new proteins and may involve increased levels of CCAAT factor mRNA. This increase in the level of a serum-responsive transcription factor suggests an intracellular pathway by which $\mathrm{pp} 60^{\mathrm{v}-s \mathrm{sc}}$ and other tyrosine kinase oncogenes could confer serum independence to gene expression. This is the first direct demonstration of changes in the activity of a transcription factor induced by a tyrosine kinase oncogene.

The constitutive activation of the CCAAT factor pathway could be an important mechanism by which several other oncogenes produce widespread changes in the repertoire of genes that are transcribed in the transformed cell. For instance, the adenovirus E1A protein stimulated transcription from the Hsp70 promoter using the basal transcription complex, particularly the TATA and the CCAAT elements (Simon et al. 1988; Williams et al. 1989|, leading us to expect that E1A-transformed cells would also contain increased levels of the CP1 or CP2 class of CCAAT-binding factors.

\section{Methods \\ Cells and culture conditions}

$3 \mathrm{Y} 1$ is an immortalized, untransformed line of rat fibroblasts. The cells were grown in Dulbecco's Eagle Medium containing $5 \%$ calf serum (5\% DEM). SR-3Y1 is derived by transformation of $3 Y 1$ with RSV (Kawai 1980). NY68-3Y1 is a line of $3 Y 1$ cells transformed by a temperature-sensitive $\mathrm{v}$-src-containing strain of RSV, tsNY68 RSV. Its derivation and properties are described elsewhere (Dutta et al. 1990). The conditions for the maintenance and infection of CEFs have been described (Hanafusa 1969).

\section{Oligodeoxynucleotides}

The oligonucleotides used were as follows:

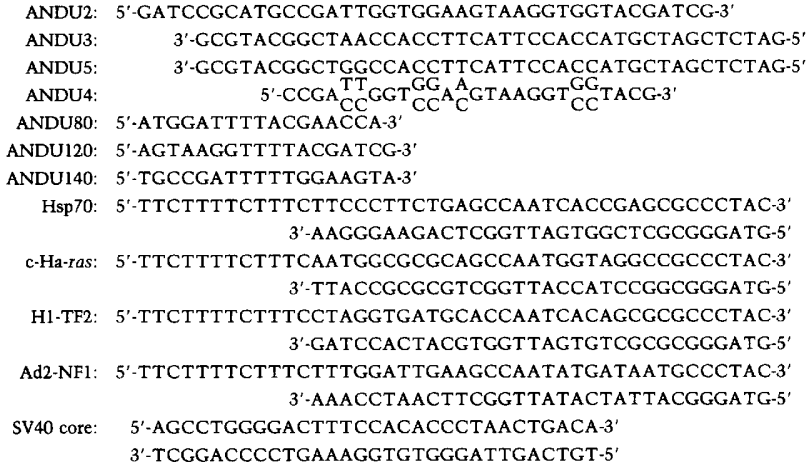

\section{Plasmids}

RSVCAT (Gorman et al. 1982b) has the RSV LTR (Fig. 1) directing transcription of the bacterial CAT gene. RSVNEO has the same fragment driving the bacterial NEO gene. We made $\triangle$ SMCAT by cutting RSVCAT at unique $S p h$ I and MstII sites, creating blunt ends, and ligating; $\triangle \mathrm{RSCAT}$ by cutting RSVCAT with EcoRI, creating blunt ends, ligating with $S p h I$ linkers, digesting with SphI and HindIII, isolating the 80-bp SphI (formerly EcoRI at -51 ) to HindIII fragment, and cloning it into the large SphI-HindIII fragment obtained from RSVCAT; and 114BgCAT by partially digesting RSVCAT with PvuI, creating blunt ends, and ligating with BgIII linkers. 51BgCAT was made similarly by partial digestion of RSVCAT with ECoRI and ligation with BgIII linkers. We cut $114 \mathrm{BgCAT}$ with BgIII and MstII, created blunt ends, and then ligated to produce $\triangle$ PMCAT. $\triangle$ PSCAT was made similarly by the use of SphI instead of MstII. Standard procedures of molecular biology were used (Maniatis et al. 1982).

We made p18LTR by cloning the 440-bp PstI-EcoRI fragment from a molecular clone of RSV 29 (Dutta et al. 1985) into the blunt-ended XbaI site in the polylinker of PEMBL18 (Dente et al. 1983) and screening for inserts in both orientations. pC contains the 90-bp EcoRI-SphI fragment of the LTR cloned between the blunted $\mathrm{XbaI}$ and the SphI sites in the polylinker of PEMBL18 and was derived from one of the orientations of $\mathrm{p} 18$ LTR by SphI digestion and ligation. pB contains the SphI-MstII fragment of the RSV LTR cloned between the blunted BamHI and the SphI sites of PEMBL18 and was also obtained from $\mathrm{p} 18$ LTR by digestion with the appropriate enzymes. p18SV2 contains the SV40 enhancer (SV40 nucleotides 108-299) in a TaqI-KpnI fragment from pXS16 (Fromm and Berg 1982) cloned between the AccI and KpnI sites of PEMBL18.

The point mutations were made starting with $\mathrm{pC}$, by use of a 
MUTAGENE kit (Bio-Rad) and mutagenic oligonucleotides ANDU4, 80, 120, and 140. The mutations were confirmed by the sequencing of miniprep DNAs using the universal primers.

pm80CAT, pm140CAT, and pm814CAT were created by the isolation of the 100-bp BamHI-SphI fragment from pC80, $\mathrm{pCl} 140$, and pC814, respectively, and the ligation of it into the 5 -kb BgIII-SphI fragment from 51BgCAT. $\triangle$ SM80CAT, $\triangle \mathrm{SM} 140 \mathrm{CAT}$, and $\triangle \mathrm{SM} 814 \mathrm{CAT}$ were derived from pm80CAT, pm140CAT, and pm814CAT, respectively, by cutting parental plasmids with $S p h I$ and MstII, treating with Klenow to create blunt ends, and ligating.

We made pAD5 by cloning the ANDU2/ANDU3 oligomer into the $B a m H I$ site of pUCI8, and pAD5pml by hybridizing ANDU2 with ANDU5 and cloning the mismatched oligonucleotide into the BamHI site of pUC18. We then sequenced miniprep plasmid DNAs from several colonies to screen for the mutant.

We digested RSVNEO with HindIII and BglII, created blunt ends, and ligated to produce the RSVminiNEO used as the internal control in the experiment described in Figure 5. The other plasmids used in that experiment were made by the substitution of the HindIII-BamHI fragment from the corresponding CAT plasmids (containing the CAT gene) with the equivalent fragment from SV2NEO containing the NEO gene. The resulting plasmids $\triangle$ RSNEO, $\triangle$ SMNEO, pm80NEO, pm140NEO, and pm814NEO had the mutant derivatives of the RSV LTR driving the intact NEO gene.

\section{Transfections}

For the transient transfection assays, the indicated amounts of plasmids were transfected into a subconfluent layer of $3 \mathrm{Y} 1 \mathrm{fi}$ broblasts using standard protocols (Cross and Hanafusa 1983). Six hours later, the medium was removed and replaced with DEM containing no serum ( $\%$ DEM) after washing the cells with Tris-buffered saline [TBS: $25 \mathrm{mM} \mathrm{HCl}(\mathrm{pH}$ 7.4), $137 \mathrm{~mm}$ $\mathrm{NaCl}, 20 \mathrm{mM} \mathrm{KCl}, 1.5 \mathrm{mM} \mathrm{Na} \mathrm{HPO}_{4}$, and $0.1 \%$ (wt/vol) glucose]. Forty-eight hours after serum starvation, the medium was supplemented with calf serum to $10 \%$, where indicated.

3Yl-NEO was made by transfecting RSVNEO into $3 Y 1$ cells and pooling $20 \mathrm{G} 418$-resistant colonies to randomize for sites of integration.

\section{CAT assays and $S 1$ nuclease assays}

CAT assays were done essentially according to Gorman et al. (1982a), using $50 \mu \mathrm{g}$ of protein and incubating for $40 \mathrm{~min}$ at $37^{\circ} \mathrm{C}$.

Total cellular RNA was prepared from the transfected cells by the method of Cox (1968). Total RNA (20 $\mu \mathrm{g})$ was mixed with gel-purified, end-labeled double-stranded probe $(100,000$ cpm) and subjected to $\mathrm{Sl}$ analysis (Sharp et al. 1980). The S1-resistant products were resolved on a $4 \%$ acrylamide-urea gel with $1 \times$ TBE buffer $(89 \mathrm{~mm}$ Tris-borate, $89 \mathrm{~mm}$ boric acid, 2 mM EDTA).

\section{Slot blots, Northerns, and nuclear run-on assays}

These assays were performed essentially as in Sugano et al. (1987) and Stoeckle et al. (1988). For slot blots, we used $3 \mu \mathrm{g}$ (1 $\mu \mathrm{g}$, where indicated) of total RNA and probed with nick-translated pRSVNEO. Northerns were performed with $5 \mu \mathrm{g}$ of total RNA electrophoresed on a formaldehyde-containing agarose gel and transferred to a nylon membrane (Zetabind). For the run-on assay, we blotted $1 \mu \mathrm{g}$ per slot of the HindIII-NcoI fragment of RSVNEO, containing the neomycin phosphotransferase-coding portion, and $5 \mu \mathrm{g}$ per slot each of pFos (the 1.0-kb PstI fragment of murine v-fos cloned into pUC18; Curran et al. 1982), pTub (1.7-kb chicken $\beta$-tubulin cDNA cloned into the PstI site of pBR322; Cleveland et al. 1980), p28S (4.8-kb SalI-EcoRI fragment of mouse 28S rRNA genomic DNA clone in pBR322; Tiemeier et al. 1977), pUC18, and $\phi X 174$ DNA. The assay, itself, was performed as described in Friedman et al. (1986).

\section{Nuclear extracts}

Nuclear extracts were prepared according to Dignam et al. (1983), as modified by Prywes and Roeder (1986). After the extracts were made, they were dialyzed against 500-1000 volumes of $\mathrm{BCl} 100$ [100 $\mathrm{mM} \mathrm{KCl}, 20 \%$ (vol/vol) glycerol, $0.2 \mathrm{mM}$ EDTA, $0.5 \mathrm{mM}$ DTT, $20 \mathrm{~mm}$ Tris- $\mathrm{HCl}$ (pH 8.0), $1 \mathrm{mM}$ PMSF, $1 \%$ Trasylol] across a Millipore VS filter $(0.025-\mu \mathrm{m}$-diam. pore size). Protein concentrations were measured using the Bio-Rad dye binding assay.

\section{Gel mobility-shift assays}

Usually, $10 \mu \mathrm{g}$ of nuclear extract was preincubated in a $24-\mu \mathrm{l}$ volume of $10 \mathrm{~mm}$ Tris- $\mathrm{HCl}(\mathrm{pH} 7.6), 1 \mathrm{mM} \mathrm{DTT}, 5 \%$ (vol/vol) glycerol, $1 \mathrm{mM} \mathrm{MgCl} 2,4 \mu \mathrm{g}$ poly[d(I-C)]/[d(I-C)], $1 \mu \mathrm{g}$ of plasmid DNA, and $60 \mathrm{mM}$ of $\mathrm{KCl}$ (or $\mathrm{KCl}+\mathrm{NaCl}$ ) for $10 \mathrm{~min}$ at $25^{\circ} \mathrm{C}$ One nanogram of probe $(100,000-200,000 \mathrm{cpm})$ in a 1- $\mu \mathrm{l}$ volume, labeled by $\mathrm{T} 4$ polynucleotide kinase or by end-filling with Klenow, was added, and incubation continued for $20 \mathrm{~min}$. The whole mixture was loaded on a $4 \%$ acrylamide gel (acrylamide/bis as $30: 0.8$ ) with $0.25 \times \mathrm{TBE}$ and electrophoresed at $180 \mathrm{~V}$ for $90 \mathrm{~min}$ at $4^{\circ} \mathrm{C}$.

\section{Acknowledgments}

We thank Dr. Nathaniel Heintz and Dr. James Darnell for their gifts of some of the oligonucleotides used in this paper; Kathy Barker, Sally Kornbluth, Bruce Mayer, Michi Hamaguchi, Ron Prywes, and Danny Lew for many helpful discussions; Kathy Barker, Bruce Mayer, and Danny Lew for reading this manuscript. Amlan Dutta helped with the plasmid constructions and their preparation. This work was supported by grants CA-44356 from the National Cancer Institute. A.D. was supported, in part, by a grant from R.J. Reynolds to the Rockefeller University. M.Y.S. was supported by a Physician's Research Training Fellowship from the American Cancer Society.

\section{References}

Almendral, J.M., D. Sommer, H. Macdonald-Bravo, J. Bunckhandt, J. Perera, and R. Bravo. 1988. Complexity of the early genetic response to growth factors in mouse fibroblasts. Mol. Cell. Biol. 8: 2140-2148.

Arrigo, S., M. Yun, and K. Beemon. 1987. cis-acting regulatory within gag genes of avian retroviruses. Mol. Cell. Biol. 7: $388-397$.

Bading, H. 1988. Determination of the molecular weight of DNA-bound protein(s) responsible for gel electrophoretic mobility shift of linear DNA fragments exemplified with purified viral myb protein. Nucleic Acids Res. 16: 5241 5248.

Bell, J.G., J.A. Wyke, and I.A. Macpherson. 1975. Transformation by a temperature sensitive mutant of Rous sarcoma virus in the absence of serum. I. Gen. Virol. 27: 127-134.

Carlberg, K., T.A. Ryden, and K. Beemon. 1988. Localization and footprinting of an enhancer within the avian sarcoma virus gag gene. J. Virol. 62: 1617-1624. 
Chen, J.H., W.S. Hayward, and H. Hanafusa. 1974. Avian tumor virus proteins and RNA in uninfected chicken embryo cells. J. Virol. 14: 1419-1429.

Chodosh, L.A., A.S. Baldwin, R.W. Carthew, and P.A. Sharp. 1988. Human CCAAT-binding proteins have heterologous subunits. Cell 53: 11-24.

Cleveland, D.W., M.A. Lopata, R.J. MacDonald, N.J. Cowan, W.J. Rutter, and M.W. Kirschner. 1980. Number and evolutionary conservation of alpha- and beta-tubulin and cytoplasmic beta- and gamma-actin genes using specific cloned cDNA probes. Cell 20: 95-105.

Connelly, S. and J.L. Manley. 1989. A CCAAT box sequence in the adenovirus major late promoter functions as part of an RNA polymerase II termination signal. Cell 57: 561-571.

Cross, F.R. and H. Hanafusa. 1983. Local mutagenesis of Rous sarcoma virus: The major sites of tyrosine and serine phosphorylation of $\mathrm{p} 60^{\text {src }}$ are dispensable for transformation. Cell 34: 597-607.

Cox, R.A. 1968. The use of guanidium chloride in the isolation of nucleic acids. Methods Enzymol. 12B: 120-129.

Cullen, B.R., K. Raymond, and G. Ju. 1985. Functional analysis of the transcription control region located within the avian retroviral long terminal repeat. Mol. Cell. Biol. 5: 438-447.

Curran, T., G. Peters, C. Van Beveren, N.M. Teich, and I.M. Verna. FBJ murine osteosarcoma virus: Identification and molecular cloning of biologically active proviral DNA. $J$. Virol. 44: 674-682.

Decker, T., D.J. Lew, Y.-S. Cheng, D.E. Levy and J.E. Darnell. 1989. Interactions of $\alpha$ and $\gamma$ interferon in the transcriptional regulation of the gene encoding a guanylate binding protein. $E M B O$ J. 8: 2009-2014.

Dente, L., G. Cesraeni, and R. Cortese. 1983. pEMBL: A new family of single stranded plasmids. Nucleic Acids Res. 11: $1645-1655$.

Dignam, J.D., R.M. Lebowitz, and R.G. Roeder. 1983. Accurate transcription initiation by RNA polymerase II in a soluble extract from isolated mammalian nuclei. Nucleic Acids Res. 11: $1475-1489$.

Dorn, A., J. Bollekens, A. Staub, C. Benoist, and D. Mathis. 1987. A multiplicity of CCAAT box-binding proteins. Cell 50: $863-872$.

Dutta, A., L.-H. Wang, T. Hanafusa, and H. Hanafusa. 1985. Partial nucleotide sequence of Rous sarcoma virus-29 provides evidence that the original Rous sarcoma virus was replication defective. I. Virol. 55: 728-735.

Dutta, A., M. Hamaguchi, and H. Hanafusa. 1990. Serum independence of transcription from the promoter of an avian retrovirus in v-src-transformed cells is a primary intracellular effect of increased levels of tyrosine phosphorylation. Proc. Nat1. Acad. Sci. (in press).

Friedman, J.M., L.E. Babiss, D.F. Clayton, and J.E. Darnell Jr. 1986. Cellular promoters incorporated into the adenovirus genome: Cell specificity of albumin and immunoglobulin expression. Mol. Cell. Biol. 6: 3791-3797.

Fromm, M. and P. Berg. 1982. Deletion mapping of DNA regions required for SV40 early region promoter function in vivo. J. Mol. Appl. Gen. 1: 457-481.

Gil, G., J.R. Smith, J.L. Goldstein, C.A. Slaughter, K. Orth, M.S. Brown, and T.F. Osborne. 1988. Multiple genes encode nuclear factor 1-like proteins that bind to the promoter for 3hydroxy-3-methylglutaryl-coenzyme A reductase. Proc. Natl. Acad. Sci. 85: 8963-8967.

Gilmartin, G.M. and J.T. Parsons. 1983. Identification of transcriptional elements within the long terminal repeat of Rous sarcoma virus. Mol. Cell. Biol. 3: 1834-1845.

Goodwin, G.H. 1988. Identification of three sequence-specific
DNA-binding proteins which interact with the Rous sarcoma virus enhancer and upstream promoter elements. $I$. Virol. 62: 2186-2190.

Gorman, C.M., L.F. Moffat, and B.H. Howard. 1982a. Recombinant genomes which express chloramphenicol acetyltransferase in mammalian cells. Mol. Cell. Biol. 2: 1044-1051.

Gorman, C.M., G.T. Merlino, M.C. Willingham, I. Pastan, and B.H. Howard. 1982b. The Rous sarcoma virus long terminal repeat is a strong promoter when introduced into a variety of eukaryotic cells by DNA-mediated transfection. Proc. Natl. Acad. Sci. 79: 6777-6781.

Gowda, S., A.S. Rao, Y.W. Kim, and R.V. Guntaka. 1988. Identification of sequences in the long terminal repeat of avian sarcoma virus required for efficient transcription. Virology 162: $243-247$.

Graves, B.J., P.F. Johnson, and S.L. McKnight. 1986. Homologous recognition of a promoter domain common to the MSV LTR and the HSV tk gene. Cell. 44: 565-576.

Greenberg, M.E. and E.B. Ziff. 1984. Stimulation of 3T3 cells induces transcription of the c-fos proto-oncogene. Nature 311: $433-438$.

Hanafusa, H. 1969. Rapid transformation of cells by Rous sarcoma virus. Proc. Natl. Acad. Sci. 63: 318-325.

Hatamochi, A., P.T. Golumbek, E. Van Schaftingen, and B. de Crombrugghe. 1988. A CCAAT DNA binding factor consisting of two different components that are both required for DNA binding. I. Biol. Chem. 263: 5940-5947.

Humphries, E.H. and H.M. Temin. 1982. Cell cycle-dependent activation of Rous sarcoma virus-infected stationary chicken cells: Avian leukosis virus group-specific antigens and ribonucleic acid. I. Virol. 10: 82-87.

-1974. Requirement for cell division for initiation of transcription of Rous sarcoma virus RNA. J. Virol. 14: 531546.

Karnitz, L., S. Faber, and R. Chalkley. 1987. Specific nuclear proteins interact with the Rous sarcoma virus internal enhancer and share a common element with the enhancer located in the long terminal repeat of the virus. Nucleic Acids Res. 15: 9841-9859.

Kawai, S. 1980. Transformation of rat cells by fusion-infection with Rous sarcoma virus. J. Virol. 34: 772-776.

Laimins, L.A., P. Tsichlis, and G. Khoury. 1984. Multiple enhancer domains in the $3^{\prime}$ terminus of the Prague strain of Rous sarcoma virus. Nucleic Acids Res. 12: 6427-6442.

Landschulz, W.H., P.F. Johnson, E.Y. Adashi, B.J. Graves, and S.L. McKnight. 1988. Isolation of a recombinant copy of the gene encoding C/EBP. Genes Dev. 2: 786-800.

Lee, W., P. Mitchell, and R. Tjian. 1987. Purified transcription factor APl interacts with TPA inducible enhancer elements. Cell. 49: $741-752$.

Leong, J.A. W. Levinson, and J.M. Bishop. 1972. Synchronization of Rous sarcoma virus production in chick embryo cells. Virology 47: 133-141.

Levy, D.E., D.S. Kessler, R. Pine, N. Reich, and J.E. Darnell. 1988. Interferon-induced nuclear factors that bind a shared promoter element correlate with positive and negative transcriptional control. Genes Dev. 2: 383-393.

Lu, K., R.A. Levine, and J. Campisi. 1989. c-ras-Ha gene expression is regulated by insulin or insulinlike growth factor and by epidermal growth factor in murine fibroblasts. Mol. Cell. Biol. 9: 3411-3417.

Luciw, P.A., J.M. Bishop, H.E. Varmus, and M.R. Capecchi. 1983. Location and function of retroviral and SV40 sequences that enhancer biochemical transformation after microinjection of DNA. Cell 33: 705-716.

Maity, S.N., P.T. Golumbek, G. Karsenty, and B. de Crom- 
brugghe. 1988. Selective activation of transcription by a novel CCAAT binding factor. Science 241: 582-585.

Maniatis, T., E.F. Fritsch, and J. Sambrook. 1982. Molecular cloning: A laboratory manual. Cold Spring Harbor Laboratory. Cold Spring Harbor, New York.

Mitsialis, S.A., J.L. Manley, and R.V. Guntaka. 1983. Localization of active promoters for eukaryotic RNA polymerase II in the long terminal repeat of avian sarcoma virus DNA. Mol. Cell. Biol. 3: 811-818.

Norton, P.A. and J.M. Coffin. 1987. Characterization of Rous sarcoma virus sequences essential for viral gene expression. I. Virol. 61: 1171-1179.

Paonessa, G., F. Gounari, R. Frank, and R. Cortese. 1988. Purification of a NF 1-like DNA-binding protein from rat liver and cloning of the corresponding cDNA. EMBO I. 7: 3115-3123.

Prywes, R. and R.G. Roeder. 1986. Inducible binding of a factor to the c-fos enhancer. Cell 47: 777-784.

Quantin, B. and R. Breathnach. 1988. Epidermal growth factor stimulates transcription of the c-jun proto-oncogene in rat fibroblasts. Nature 334: 538-539.

Ryden, T.A. and K. Beemon. 1989. Avian retroviral long terminal repeats bind CCAAT/enhancer-binding protein. Mol. Cell. Biol. 9: 1155-1164.

Ryder, K., L. Lau, and D. Nathans. 1988. A gene activated by growth factors related to the oncogene v-jun. Proc. Natl. Acad. Sci. 85: 1487-1491.

Santoro, C., N. Mermod, P.C. Andrews, and R. Tjian. 1988. A family of human CCAAT-box-binding proteins active in transcription and DNA replication: Cloning and expression of multiple cDNAs. Nature 334: 218-224.

Sealey, L. and R. Chalkley. 1987. At least two nuclear proteins bind specifically to the Rous sarcoma virus long terminal repeat enhancer. Mol. Cell. Biol. 7: 787-798.

Sen, R. and D. Baltimore. 1986. Inducibility of $\kappa$ immunoglobulin enhancer-binding protein NF- $\mathrm{KB}$ by a post-translational mechanism. Cell 47: 921-928.

Sharp, P.A., A.J. Berk, and S.M. Berget. 1980. Transcription maps of adenovirus. Methods Enzymol. 65: 750-768.

Simon, M.C., T.M. Fisch, B.J. Benecke, J.R. Nevins, and N. Heintz. 1988. Definition of multiple functionally distinct TATA elements, one of which is a target in the hsp70 promoter for Ela regulation. Cell 52: 723-729.

Stoeckle, M.Y., S. Sugano, A. Hampe, A. Vashishtha, D. Pellman, and H. Hanafusa. 1988. 78-Kilodalton glucose-regulated protein is induced in Rous sarcoma virus-transformed cells independently of glucose deprivation. Mol. Cell. Biol. 8: $2675-2680$.

Sugano, S., M.Y. Stoeckle, and H. Hanafusa. 1987. Transformation by Rous sarcoma virus induces a novel gene with homology to a mitogenic platelet protein. Cell 49: 321-328.

Temin, H.M. 1967. Studies on carcinogenesis by avian sarcoma viruses V. Requirement for new DNA synthesis and for cell division. J. Cell. Physiol. 69: 53-64.

Tiemeier, D.C., S.M. Tilghman, and P. Leder. 1977. Purification and cloning of a mouse ribosomal gene fragment in coliphage lambda. Gene 2: 173-191.

Todaro, G.J., G.K. Lazsr, and H. Green. 1965. The initiation of cell division in a contact-inhibited mammalian cell line. $J$. Cell. Comp. Physiol. 66: 325-334.

Treisman, R. 1985. Transient accumulation of c-fos RNA following serum stimulation requires a conserved 5 ' element and c-fos $3^{\prime}$ sequences. Cell 42: 889-902.

Wang, L.-H., M. Beckson, S.A. Anderson, and H. Hanafusa. 1984. Identification of viral sequence required for the generation of recovered avian sarcoma viruses and characterization of a series of replication-defective recovered avian sar- coma viruses. J. Virol. 49: 881-891.

Weber, F. and W. Schaffner. 1985. Enhancer activity correlates with the oncogenic potential of avian retroviruses. EMBO J. 4: 949-956.

Williams, G.T., T.K. McClanahan, and R.I. Morimoto. 1989. Ela transactivation of the human Hsp70 promoter is mediated through the basal transcription complex. Mol. Cell. Biol. 9: 2574-2587.

Wu, B.J., R.E. Kingston, and R.I. Morimoto. 1986. Human hsp70 promoter contains at least two distinct regulatory domains. Proc. Natl. Acad. Sci. 83: 629-633.

Yamamoto, T., B. de Crombrugghe, and I. Pantan. 1980. Identification of a functional promoter in the long terminal repeat of Rous sarcoma virus. Cell 22: 787-797. 


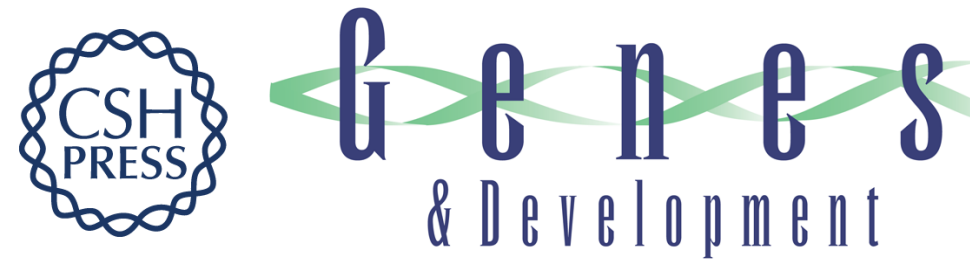

\section{Serum and v-src increase the level of a CCAAT-binding factor required for transcription from a retroviral long terminal repeat.}

A Dutta, M Y Stoeckle and H Hanafusa

Genes Dev. 1990, 4:

Access the most recent version at doi:10.1101/gad.4.2.243

References This article cites 64 articles, 29 of which can be accessed free at:

http://genesdev.cshlp.org/content/4/2/243.full.html\#ref-list-1

License

Email Alerting

Service

Receive free email alerts when new articles cite this article - sign up in the box at the top right corner of the article or click here.

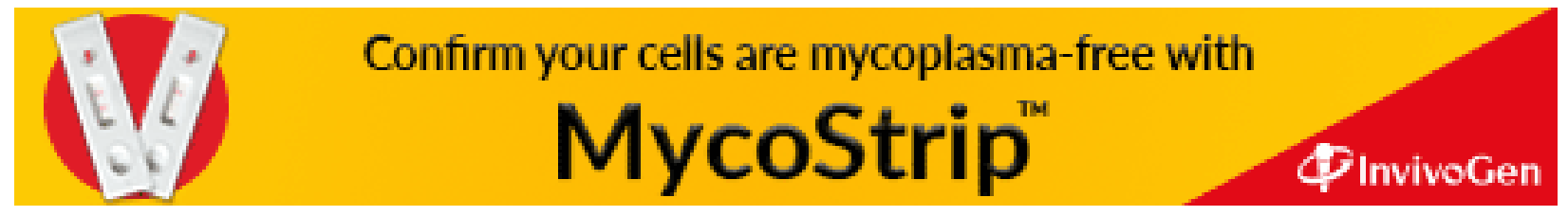

